\title{
Preterm Birth and Childhood Psychiatric Disorders
}

\author{
SAMANTHA JOHNSON AND NEIL MARLOW \\ Department of Health Sciences [S.J.], University of Leicester, Leicester LE1 6TP, United Kingdom; Institute for Women's Health [N.M.], \\ University College London, London WCIE 6AU, United Kingdom
}

\begin{abstract}
Epidemiologic studies have, for many years, identified preterm birth as a significant risk factor for psychiatric disorders. There has been a recent resurgence of interest in neurobehavioral outcomes after preterm birth. In this article, we review clinical cohort studies of the prevalence, etiology, and risk factors for psychiatric sequelae in expreterm children. Studies using diagnostic psychiatric evaluations are few in number but typically report a 3- to 4-fold increased risk for disorders in middle childhood. Our review of studies reveals a "preterm behavioral phenotype" characterized by an increased risk for symptoms and disorders associated with inattention, anxiety, and social difficulties. The most contemporary studies have also reported a markedly increased prevalence of autism spectrum disorders (ASD) in preterm populations. Our examination of the correlates and comorbidities of psychiatric disorders is indicative of a different causative pathway that may be associated with altered brain development after preterm birth. Despite the low population attributable risk, the frequency of these symptoms and disorders means that psychiatric screening is likely to be beneficial in this vulnerable population. (Pediatr Res 69: 11R-18R, 2011)
\end{abstract}

$\mathrm{P}$ erinatal factors have long been implicated in the genesis of psychiatric disorders, most notably in schizophrenia, but the role such factors play in the causal pathway is less well understood. For a long time, a range of biological insults, including preterm birth and LBW, were considered nonspecific triggers for later disorders (1). More recently, epidemiologic studies in the general population have identified significant inverse incremental associations with birthweight and/or GA at birth: the risk and prevalence of psychiatric morbidity increase as birthweight and GA decrease (2). Although these associations are not confined to those with very LBW (VLBW; birthweight $\leq 1500$ g) or very preterm birth (VPT; $<32$ wk gestation), the risk is greatest for these groups $(2,3)$. Preterm birth and LBW have also been identified as risk factors for specific psychiatric disorders, namely emotional disorders (2-5), attention deficit/hyperactivity disorders (ADHD) (6), and autism spectrum disorders (ASD) (7-10).

The casual pathway to these disorders must be interpreted in the context of the known neurologic sequelae of preterm birth, namely focal brain injury and altered brain development (11). These are manifest in the relationship between immaturity and CP (12) and low intelligent quotient (IQ) $(13,14) /$ learning difficulties (15), respectively. The prevalence of impaired outcomes rises more steeply as GA falls below $32 \mathrm{wk}$ and thus one might predict that psychiatric morbidity would be most prevalent in such populations. Where birthweight has

Received November 11, 2010; accepted December 14, 2010.

Correspondence: Samantha Johnson, Ph.D., Department of Health Sciences, University of Leicester, 22-28 Princess Road West, Leicester, LE1 6TP United Kingdom; e-mail: sjj19@le.ac.uk been used to define populations, there may be differences in outcomes stemming from the excess of children born after fetal growth restriction, which have independent effects on psychiatric morbidity (16).

Several studies have now followed the progress of very immature cohorts born in the 1980s and 1990s through to adolescence and adult life, and have sought to define the full spectrum of impairment, including psychiatric disorders. We place emphasis on population-based studies, particularly for cohorts born in the 1990s, because these reflect the most contemporaneous outcomes relevant to current public health concerns. In this article, we review clinical studies of outcomes in middle childhood and beyond and present an overview of behavioral and psychiatric morbidity in relation to neurodevelopmental correlates and early predictors of disorders in preterm populations.

\section{Prevalence and Profile of Behavior Problems}

The majority of studies investigating morbidity for preterm $(<37 \mathrm{wk}) / \mathrm{LBW}(<2500 \mathrm{~g})$ cohorts have used behavioral screening questionnaires, such as the widely used Child Behavior Checklist (CBCL) (17). These provide cost- and timeefficient measures for large-scale use. Studies using screening questionnaires have shown that there is a significant excess of behavior problems in most preterm/LBW cohorts (18), and prevalence estimates range from 19 to $40 \%$ for LBW (19-22), 13 to $46 \%$ for VPT/VLBW (16,23-26), and 19 to $32 \%$ for extremely preterm (EPT: $<26$ wk)/extremely LBW (ELBW: $\leq 1000 \mathrm{~g})(27-30)$ children. There is less consensus for children born moderate to late preterm (32-36 wk of gestation); some report an excess of behavior problems $(31,32)$, whereas others report no significant difference from term peers (33). A GA-related gradient in outcomes is supported by a number of studies in which the prevalence of behavior problems was greater in those born at lower gestations or with LBW $(26,34)$.

Variable findings are reported regarding the risk for internalizing and externalizing problems. In a meta-analysis of 16 case-control studies of school-aged VPT/VLBW children pub-

\footnotetext{
Abbreviations: ADHD, attention deficit hyperactivity disorder; ADHD/C, attention deficit hyperactivity disorder/combined subtype; ADHD/H, attention deficit hyperactivity disorder/hyperactive subtype; ADHD/I, attention deficit hyperactivity disorder/inattentive subtype; ASD, autism spectrum disorders; DSM, diagnostic and statistical manual of mental disorders; ELBW, extremely LBW; EPT, extremely preterm; VLBW, very LBW; VPT, very preterm
} 
lished in 1980-2001, 9 of 13 studies reported an increase in internalizing symptoms and 9 of 12 in externalizing symptoms (18). In a later meta-analysis of nine case-control studies of VPT (here defined as birth $<34 \mathrm{wk}$ )/VLBW children published between 1998 and 2008, parents rated their children as having more internalizing problems but combined effect sizes for parent- and teacher-rated externalizing problems were nonsignificant (35). More recent studies continue to report conflicting results regarding the risk for internalizing $(28,31,34)$ and externalizing problems $(23)$. Given the inverse relationship with maturity, some of this difference may be due simply to heterogeneity in population definitions.

There is greater consensus at the narrowband level in terms of behavioral profiles identified. Hille et al. (36) report crosscultural outcomes in four population-based ELBW cohorts born in 1977-1987 and assessed using the CBCL. Externalizing scores were not elevated in any cohort and internalizing scores were increased only in one. In contrast, all four cohorts had significantly increased scores for social, thought, and attention scales (elevated by $0.5-1.2$ SD relative to countryspecific controls) and there was a marked absence of aggressive/ delinquent behavior. In one cohort, scores for somatic complaints and anxiety/depression were also elevated. Similarly, in a more contemporary population of Swedish EPT children born 19901992, social, thought, and attention scales were 0.75-1.3 SD higher than controls (28). Studies using other popular screening tools, such as the Strengths and Difficulties Questionnaire (37), typically reveal a similar profile of increased risk for attention/ hyperactivity, social, and emotional problems in preterm/LBW populations $(19,24,29,38,39)$.

It is notable that the majority of studies report higher group mean scores on both broadband and narrowband scales, even where the proportion of children scoring in the abnormal range is not significantly increased. This implies that many children may have symptoms that fail to reach clinical significance. This is a consistent finding in studies using dimensional measures of symptomatology in VPT/VLBW populations, particularly for ADHD and ASD.

Although differences in screening tools, population definitions and age at assessment make direct comparisons of prevalence rates difficult, consistencies confirm a "preterm behavioral phenotype" characterized by inattention/hyperactivity, social, and emotional difficulties and, in general, a greater risk for internalizing rather than externalizing problems, which are more frequent at lower GAs. In the next section, we provide evidence to show that these findings are mirrored in diagnostic studies of psychiatric morbidity in preterm populations, which are characterized by significantly increased rates of ADHD, ASD, and emotional disorders.

\section{Prevalence and Prediction of Psychiatric Disorders}

Studies using diagnostic evaluations are required to provide definitive evidence of an increased prevalence of disorders in preterm/LBW populations. There is a relative paucity of such studies as psychiatric evaluations are costly and difficult to implement in large-scale investigations. Although the majority of those that exist have used questionnaires that yield symp- tom data corresponding with Diagnostic and Statistical Manual of Mental Disorders (DSM) diagnostic criteria (40), a small number have used more rigorous evaluations. Despite very different methodologies, these report similar prevalence estimates across a range of different populations (Table 1).

In two early studies using DSM-based questionnaires, Szatmari et al. $(41,42)$ reported 24 to $27 \%$ prevalence of disorders in ELBW children. These rates were not significantly increased compared with controls, and in both studies, the risk of disorders was specific to ADHD. In the first study of psychopathology in ELBW children born in the 1990s, Hack et al. (43) reported a significant excess of psychiatric morbidity compared with controls with $32 \%$ prevalence of disorders in ELBW children. In all three studies, the prevalence of disorders in the control group (15-16\%) was higher than the $10 \%$ typically observed in the general population (44) and may thus reflect that the measures were essentially screening tools.

We are aware of only five diagnostic studies (Table 1), of which four have reported 22 to $27 \%$ prevalence of disorders in LBW/VLBW children born in the 1980s $(16,19,45,46)$. In the UK EPICure Study, a national prospective cohort study of all births $\leq 25$ wk of gestation in the UK and Ireland in 1995, we have reported that $23 \%$ met criteria for DSM-IV-TR (40) defined psychiatric disorders, rising to $25 \%$ after imputation to account for selective loss to follow-up of more impaired survivors (Fig. 1) (47). Overall, these five studies have reported remarkably similar prevalence estimates and ORs indicating a 3- to 4-fold increased risk for psychiatric disorders in childhood.

Where authors have investigated neurodevelopmental correlates, psychiatric disorders have been found to be significantly associated with poor cognitive function $(43,45,47)$. Although some authors have found that the overall risk of disorders remains significant after excluding those with low IQ (scores $<-1 \mathrm{SD})(16,43)$, we have reported that moderate/severe cognitive impairment (scores $<-2 \mathrm{SD}$ ) but not neurological or sensory disability, accounted for the significant excess of disorders in EPT children (47). In VPT populations, males have typically been found to be at greater risk for neuro-cognitive impairment compared with females and may therefore be at increased risk for psychiatric sequelae $(48,49)$. However, results regarding gender differences for psychiatric disorders are more equivocal with some reporting a increased risk of disorders for ELBW boys (45) and not others $(16,19,46,47)$. The findings are also variable regarding co-morbidity: some authors have reported increased risk for comorbid psychiatric disorders compared with controls (43) in contrast to others (47). However, variation in the pattern of comorbidities is of greater theoretical significance and is described in the following sections.

Early identification of those at risk for psychiatric disorders would facilitate timely psychiatric referral and provision of support for children and their families. Studies attempting to identify early predictors of psychiatric disorders have produced inconsistent findings. Some report no associations with neonatal variables $(19,46)$, whereas others have reported significant associations with LBW, decreasing GA and smaller head circumference (50). Among EPT children at $11 \mathrm{y}$ of age, we observed no significant univariate associations with any 
Table 1. Studies reporting the prevalence of psychiatric disorders using DSM diagnostic criteria in preterm and LBW children

\begin{tabular}{|c|c|c|c|c|c|c|c|}
\hline \multirow[b]{2}{*}{ Study reference } & \multirow[b]{2}{*}{ Control } & \multirow[b]{2}{*}{ Index } & \multirow[b]{2}{*}{ Age (y) } & \multirow[b]{2}{*}{ Evaluation } & \multicolumn{2}{|c|}{ Prevalence of disorders } & \multirow[b]{2}{*}{ OR $(95 \% \mathrm{CI})$} \\
\hline & & & & & Control $(\%)$ & Index $(\%)$ & \\
\hline \multicolumn{8}{|c|}{$\begin{array}{l}\text { Diagnostic psychiatric } \\
\text { evaluations }\end{array}$} \\
\hline 47 & $n=152$ & $\begin{array}{l}\text { EPT } \\
n=219 \\
1995\end{array}$ & 11 & DAWBA & 9 & 23 & $3.2(1.7-6.2)$ \\
\hline 16 & $n=83$ & $\begin{array}{c}\text { VLBW } \\
n=56 \\
1986-1988\end{array}$ & 14 & KSADS & 7 & 25 & $4.3(1.5-12.0)$ \\
\hline 19 & $n=130$ & $\begin{array}{c}\text { LBW } \\
n=130 \\
1986-1988\end{array}$ & 11 & CAS & 9 & 27 & $3.1(1.5-6.5)$ \\
\hline 46 & $n=148$ & $\begin{array}{c}\text { VLBW } \\
n=136 \\
1980-1983\end{array}$ & 12 & CAPA & 10 & 28 & $3.4(1.8-6.6)^{*}$ \\
\hline 45 & None & $\begin{array}{c}\text { LBW } \\
n=564 \\
1984-1987\end{array}$ & 6 & DISC 2.1P & N/A & 22 & N/A \\
\hline \multicolumn{8}{|l|}{$\begin{array}{c}\text { Questionnaire-based } \\
\text { diagnoses }\end{array}$} \\
\hline 43 & $n=176$ & $\begin{array}{c}\text { ELBW } \\
n=219 \\
1992-1995\end{array}$ & 8 & CSI-4 & 15 & 32 & $2.7(1.6-4.5)^{*}$ \\
\hline 42 & $n=145$ & $\begin{array}{c}\text { ELBW } \\
n=129 \\
1977-1981\end{array}$ & 8 & SDI & 16.2 & 26.7 & NS \\
\hline 41 & $n=208$ & $\begin{array}{c}\text { ELBW } \\
n=82 \\
1980-1982\end{array}$ & 5 & SDI & 16.3 & 24.2 & NS \\
\hline
\end{tabular}

* OR $(95 \% \mathrm{CI})$ calculated retrospectively from data provided in the article.

DAWBA, Development and Well Being Assessment; KSADS, Kiddie-Schedule for Affective Disorders and Schizophrenia; CAS, Children Assessment Schedule; CAPA, Child and Adolescent Psychiatric Assessment; DISC 2.1P, Diagnostic Schedule for Children-Parent Version 2.1P; CSI-4, Parent Child

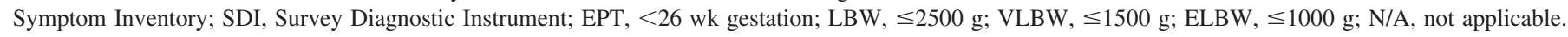

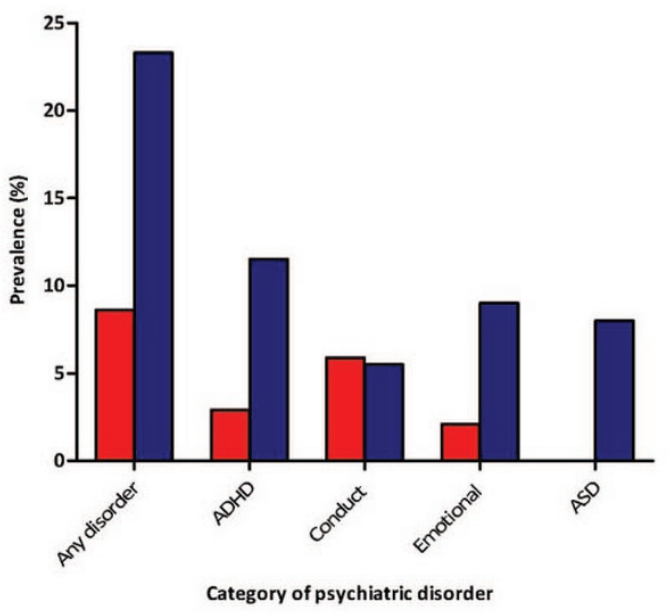

Figure 1. Prevalence of psychiatric disorders at $11 \mathrm{y}$ of age in a whole population-based cohort of 219 EPT $(<26 \mathrm{wk})$ children (blue columns) and 152 term-born classmates (red columns) in the UK EPICure Study.

neonatal variables although there was marginally greater risk for boys and vaginal breech deliveries and, in some analyses, neonatal necrotizing enterocolitis. In contrast, we found greater predictive accuracy using later neurodevelopmental measures; in particular, parent-reported internalizing behavior problems at $2.5 \mathrm{y}$ and conduct and attentional problems, and neurocognitive impairment at 6 y were associated with psychiatric disorders at
11 y (47). In all these studies, significant associations were found after adjustment for socioeconomic factors and thus highlight the overwhelming effect of perinatal risk (50). Thus, longitudinal neurodevelopmental assessments and behavioral screening may highlight those children who are at risk for later psychiatric morbidity, providing the opportunity for early diagnosis and intervention. Early predictors of specific psychiatric disorders are discussed in the following sections.

\section{Attention Deficit/Hyperactivity Disorder}

ADHD is the most prevalent and frequently studied psychiatric disorder in preterm/LBW populations. All but one (51) of the earliest studies using DSM-based questionnaires reported a significant excess of ADHD with prevalence rates ranging 16 to $19 \%$ and ORs of 2 to 3 in VLBW/ELBW children $(41,42,52)$. More recent studies report prevalence estimates of 9 to $11 \%$ in VPT/VLBW $(26,53)$ and 17 to $20 \%$ in EPT/ ELBW children $(26,27)$, indicating a GA-related gradient (26). The pooled relative risk (RR) for ADHD in VPT/VLBW survivors in six studies was 2.64 (95\% CI, 1.85-3.78) (18) and a recent epidemiological study has reported an RR of 2.7 (95\% CI, 1.8-4.1) in children born $<34$ wk (6).

Of the five diagnostic studies, four reported varying prevalence estimates ranging from 7 to $23 \%$ in LBW/VLBW children born in the 1980s (Table 2) $(16,19,45,46)$. Increased risk has also been 
Table 2. Studies reporting the prevalence of ADHD using DSM-based diagnostic criteria in preterm and LBW children

\begin{tabular}{|c|c|c|c|c|c|c|c|c|}
\hline \multirow[b]{2}{*}{$\begin{array}{l}\text { Study } \\
\text { reference }\end{array}$} & \multirow[b]{2}{*}{ Control } & \multirow[b]{2}{*}{ Index } & \multirow[b]{2}{*}{ Age (y) } & \multirow[b]{2}{*}{ Assessment } & \multicolumn{2}{|c|}{ Prevalence of ADHD } & \multirow[b]{2}{*}{ OR $(95 \% \mathrm{CI})$} & ADHD subtypes \\
\hline & & & & & $\begin{array}{c}\text { Control } \\
(\%)\end{array}$ & $\begin{array}{l}\text { Index } \\
(\%)\end{array}$ & & Control vs. index (OR; 95\% CI) \\
\hline \multicolumn{9}{|c|}{$\begin{array}{c}\text { Diagnostic psychiatric } \\
\text { evaluations }\end{array}$} \\
\hline 47 & $n=152$ & $\begin{array}{l}\text { EPT } \\
n=219 \\
1995\end{array}$ & 11 & DAWBA & 2.9 & 11.5 & $4.3(1.5-13.0)$ & $\begin{array}{l}\text { ADHD/I: } 0.7 \text { vs. } 7.1 \%(10.5 ; 1.4-81.1) \\
\text { ADHD/H: } 0 \text { vs. } 0 \% \\
\text { ADHD/C: } 2.2 \text { vs. } 4.4 \%(2.1 ; 0.5-7.9)\end{array}$ \\
\hline 16 & $n=83$ & $\begin{array}{c}\text { VLBW } \\
n=56 \\
1986-1988\end{array}$ & 14 & KSADS & 1 & 7 & NS & Not studied \\
\hline 19 & $n=130$ & $\begin{array}{l}\text { LBW } \\
n=130 \\
1986-1988\end{array}$ & 11 & CAS & 1 & 10 & $14.7(1.8-114)$ & Not studied \\
\hline 46 & $n=148$ & $\begin{array}{c}\text { VLBW } \\
n=136 \\
1980-1983\end{array}$ & 12 & CAPA & 6 & 23 & $4.6(2.1-9.9)^{*}$ & $\begin{array}{l}\text { ADHD/I: } 2.7 v s .8 .1 \%(p<0.05) \\
\text { ADHD/H: } 1.4 v s .6 .6 \%(p<0.05) \\
\text { ADHD/C: } 2.0 v s .8 .1 \%(p<0.05)\end{array}$ \\
\hline 45 & None & $\begin{array}{c}\text { LBW } \\
n=564 \\
1984-1987\end{array}$ & 6 & DISC $2.1 \mathrm{P}$ & N/A & 15.6 & N/A & Not studied \\
\hline 52 & $n=80$ & $\begin{array}{c}\text { VLBW } \\
n=88 \\
1978-1980\end{array}$ & 7 & $\begin{array}{l}\text { Clinical } \\
\text { observation }\end{array}$ & 7.5 & 18 & $2.7(1.0-7.4)^{*}$ & Not studied \\
\hline \multicolumn{9}{|c|}{$\begin{array}{c}\text { Questionnaire-based } \\
\text { diagnoses }\end{array}$} \\
\hline 43 & $n=176$ & $\begin{array}{c}\text { ELBW } \\
n=219 \\
1992-1995\end{array}$ & 8 & CSI-4 & $5 \%$ & $17 \%$ & $4.2(1.9-9.1)$ & $\begin{array}{l}\text { ADHD/I: } 3 \text { vs. } 10 \%(4.1 ; 1.5-11.1) \\
\text { ADHD/H: } 2 \text { vs. } 3 \%(1.9 ; 0.5-8.0) \\
\text { ADHD/C: } 0.6 \text { vs. } 5 \%(8.1 ; 1.0-64.6)\end{array}$ \\
\hline
\end{tabular}

Studies using DSM-based questionnaires are included where these have assessed the prevalence of ADHD subtypes.

* OR $(95 \%$ CI) calculated retrospectively from data provided in the article.

DAWBA, Development and Well Being Assessment; KSADS, Kiddie-Schedule for Affective Disorders and Schizophrenia; CAS, Children Assessment Schedule; CAPA, Child and Adolescent Psychiatric Assessment; DISC 2.1P, Diagnostic Schedule for Children-Parent Version 2.1P; CSI-4, Parent Child Symptom Inventory; EPT, <27 wk gestation; LBW, $\leq 2500$ g; VLBW, $\leq 1500$ g; ELBW, $\leq 1000$ g; N/A, not applicable; ADHD/C, ADHD-combined subtype using DSM-IV-TR diagnostic criteria; NS, not significant.

described in cohorts born in the 1990s: $11.5 \%$ prevalence in EPT children (Fig. 1) (47) and 17\% in those with ELBW (43). Although these two studies used measures with different diagnostic accuracy, the ORs of 4.3 and 4.2, respectively, are remarkably similar. Thus, existing reports indicate a 2 - to 3 -fold increased risk for ADHD in VPT/VLBW children and a 4-fold increased risk in those born EPT/ELBW (Table 2).

The correlates and comorbidities of ADHD in preterm children are indicative of a different clinical presentation than for children born at term. First, the male predominance in ADHD in the general population (44) is typically not observed in preterm cohorts $(16,19,47)$. Second, the association with comorbid conduct disorders in the general population is lacking in preterm children; there is no significant increase in conduct disorders in preterm/LBW populations (16,4143,45-47), and VPT/VLBW children with ADHD are less likely to have comorbid conduct disorders than term children with ADHD $(19,42,47)$, Third, there appears to be a weaker association of ADHD with sociodemographic and family risk in preterm cohorts than in the general population (44), in that, there is a closer association between ADHD and medical variables than social factors $(16,41,42,46,50,54)$.

Finally, VLBW/VPT birth appears to be associated with a greater risk for symptoms of inattention than hyperactivity/ impulsivity. Using rating scales that differentiate these two dimensions, preterm children were found to have significantly higher mean scores than controls for inattention but not hyperactivity (16). In more recent studies of VPT, EPT, and ELBW children, there are markedly larger effect sizes for inattention compared with hyperactivity as rated by both parents and teachers $(43,55)$. Parallel findings are reported in diagnostic studies using DSM-IV-based definitions (Table 2). In an early study, Botting et al. found higher rates of ADHD/ inattentive $(\mathrm{ADHD} / \mathrm{I})$ compared with $\mathrm{ADHD} /$ hyperactive $(\mathrm{ADHD} / \mathrm{H})$ subtype disorders in VLBW children. In two more recent studies, the excess risk for ADHD in EPT/ELBW children was accounted for by a specific risk for ADHD/I and ADHD/H were not significantly increased in comparison with term children $(43,47)$. We also observed that there was no significant increase in hyperkinetic disorders classified using International Classification of Diseases (ICD)-10 (56) criteria, in which features of hyperactivity are required for diagnosis (47). It thus seems preferable to use DSM-IV-TR (40) classifications in preterm children.

These converging strands of evidence are indicative of a different causative pathway for ADHD in preterm populations. This has led authors to suggest that VPT/VLBW children are susceptible to a "purer," more biologically determined form of attention deficit associated with a neurological etiology $(36,41)$. VPT/VLBW birth is associated with cognitive impairment and impaired brain growth, evidenced by structural abnormalities on MRI $(11,57,58)$. A number of studies have 
provided evidence indicative of a mediating role of neurodevelopmental factors in the relationship between preterm birth and ADHD, with significant group differences being accounted for by the high prevalence of cognitive impairment in EPT/ELBW children $(41,42,47)$. Significant independent associations between ADHD symptoms and indices of brain structure and maturation in preterm populations including head circumference, intraventricular hemorrhage, parenchymal lesions, and/or ventricular enlargement on neonatal cranial ultrasound and structural MRI at school-age are reported (45,50,59-61). Indredavik et al. (62) found that ADHD symptoms were associated with reduction in white matter volumes and thinning of the corpus callosum in VLBW adolescents after adjustment for sex and socioeconomic factors. The correlation between symptoms and white matter volume was due to a specific association with inattention scores. Skranes et al. (63) also found that inattention but not hyperactivity scores were associated with fractional anisotropy measurements of white matter in VLBW adolescents. They also found that ADHD was associated with lower fractional anisotropy values in six different anatomical areas and speculate that this may be indicative of disturbed white matter connectivity in extensive areas throughout the brain.

ADHD/I and other ADHD may be considered as separate disorders that are characterized by dissociable cognitive, behavioral, and neurobiological profiles with different patterns of comorbidities and responses to medication (64-66). In contrast to classical ADHD, children with ADHD/I can be considered as having a childhood-onset dysexecutive syndrome that is characterized by social difficulties related to shyness and withdrawal, internalizing problems, an absence of aggression/delinquent behavior, academic difficulties, and primary deficits in working memory and processing speed (67). This profile bears a striking resemblance to that associated with VPT birth (68-70). Hyperactivity in preterm survivors may be accounted for by poor general cognitive ability, but inattention may be a specific feature of development after preterm birth that is associated with specific executive deficits. This is supported by Nadeau et al. (71) who observed that general cognitive ability mediated the relationship between EPT birth and hyperactivity, whereas the relationship between EPT birth and inattention was mediated specifically by working memory.

In summary, in VPT/VLBW children, there is evidence of increased risk for the inattentive subtype of ADHD, itself associated with impairment in normal brain growth and maturation. Further research is needed to elucidate the etiology and clarify the profile of impairment associated with such deficits to improve identification, management, and treatment of $\mathrm{ADHD}$ in preterm populations.

\section{Autism Spectrum Disorders}

A review of epidemiologic studies of ASD in the general population has provided a best current prevalence estimate of approximately $0.2 \%$ for narrowly defined autistic disorder and $0.6 \%$ for the broader category of ASD (72). Epidemiologic studies provide evidence that preterm birth and LBW are important risk factors for ASD $(7,9,10,73)$. Although studies using behavioral screening questionnaires have consistently identified a high level of peer-related problems in VPT/ VLBW children, until recently, there were few clinical studies of ASD in preterm populations.

In one of the earliest cohort studies of psychiatric outcomes, it is interesting to note that Szatmari et al. (41) excluded from follow-up two ELBW children with ASD as the disorders of interest could not be assessed in the presence of ASD. These children represented $2.2 \%$ of their surviving ELBW cohort and this was perhaps one of the earliest references to ASD in ex-preterm children. In more mature children, the frequency of symptoms and diagnoses is relatively low. For example, in 130 LBW children, 1 child $(0.8 \%)$ had clinical symptoms of Asperger's disorder (19) and 1 of 56 (1.8\%) was assigned a diagnosis of Asperger's disorder using a psychiatric evaluation (16).

Only two studies have investigated ASD in contemporary populations born in the 1990s. Using a DSM-based screening questionnaire, Hack et al. (43) reported that 3.6\% of ELBW children met criteria for ASD at $8 \mathrm{y}$ of age. In the only diagnostic study of EPT children at $11 \mathrm{y}$, we have reported that, although the prevalence of positive screening was high in middle childhood (16\%), only $8 \%$ (16 children) were assigned diagnoses of ASD compared with none of the classmates (Fig. 1). Among these with ASD, 13 had autistic disorder and 3 pervasive developmental disorder-not otherwise specified (PDD-NOS) (47,74). This indicates a prevalence that is around 65 times higher than general population estimates for autistic disorder and 4-12 times higher for ASD $(44,72,75)$. No children had Asperger's disorder; this was anticipated because the high level of neurodevelopmental delay in EPT children means they are unlikely to fulfil diagnostic criteria, which include unimpaired cognitive and language development in infancy. Although this clearly confirms the significant risk for ASD associated with EPT birth, prevalence at more mature GAs requires further investigation.

In two studies that have evaluated the role of screening for ASD in infancy using the Modified-Checklist for Autism in Toddlers (M-CHAT) questionnaire (76) but without a follow-up interview, 21-25\% of VPT/VLBW infants screened positive for autistic features at $2 \mathrm{y}$ of age compared with $<5 \%$ in term infants $(77,78)$. Although this raises awareness of the high prevalence of autistic symptomatology already present in infancy in preterm survivors, the specificity of screening is confounded by the high rate of developmental delay in these populations and the rates of confirmed diagnoses later in childhood are likely to be much lower (79). The predictive validity of screening in infancy for later ASD requires further investigation in preterm populations.

Similar to ADHD, studies that have used dimensional measures have shown a generally increased liability to ASD symptomatology in preterm children (74). Compared with term children, EPT/ELBW children have significantly higher mean scores, greater variability in scores, and are more likely to have subclinical level of symptoms $(19,39,43,74)$. Children who meet diagnostic criteria thus appear to represent the 
extreme end of a distribution of symptoms that are generally increased in preterm survivors.

Although ASD are generally considered to be genetic in origin, ASD in preterm children are associated with different clinical profiles and comorbidities indicative of different etiological mechanisms, in a similar fashion to ADHD. The generally high prevalence of autism spectrum symptoms has led some authors to suggest that socialization difficulties may be qualitatively different from classical autistic features and may be mediated by inattention and distractibility $(19,36)$. Autism spectrum symptoms are strongly associated with cognitive impairment $(74,78)$, and low IQ has been shown to account for more than half the excess of sociocommunicative problems in EPT children at $11 \mathrm{y}$ of age (74). Symptoms were also significantly associated with smaller head circumference, in contrast to the association with larger head circumference in the general population. On multivariable analysis, an abnormal neonatal cranial ultrasound scan and cognitive impairment were independently associated with ASD symptoms (74). In studies combining psychiatric assessments and cranial MRI, autism spectrum symptoms in VLBW children were associated with white matter reduction and ventricular enlargement (62), more global white matter abnormalities (63) and with cerebellar-hemorrhagic injury in infancy (77). Autism spectrum symptoms have also been associated with bronchopulmonary dysplasia, an association that may be mediated by the effects of low oxygen tensions on outcome (43).

This overall pattern is commensurate with a nongenetic, environmental origin for ASD in association with aberrant brain development and brain injury associated with VPT birth (80). We have also noted the striking similarity in the cognitive and behavioral profiles found in studies of EPT survivors (74) and those of Romanian adoptees, the latter of which are at risk for autistic spectrum symptoms that are associated with attachment disorder, ADHD, and cognitive impairment (81). Both groups have experienced highly abnormal early physical and psychosocial environments during a potentially critical period for development of the social brain and thus psychosocial factors may interact to affect brain maturation in EPT children $(82,83)$. Others have suggested that factors specific to the experience of parenting an EPT child, such as infant regulatory difficulties and impaired parent-infant interaction, may be also be implicated in the development of behavioral and socioemotional disorders in this population (27).

\section{Emotional Disorders}

A number of studies have reported significantly increased emotional problems in VLBW and EPT/ELBW children as rated by parents and teachers $(25,28,29,38,39,84,85)$. However, the majority of screening measures combine ratings of anxiety and depression, rendering it difficult to differentiate between these dimensions.

Diagnostic studies typically indicate a specific risk for anxiety rather than depression. Although one study reported no significant difference in the prevalence of emotional disorders between LBW and normal birthweight children (19), two studies have reported a significant excess of anxiety but not depressive disorders in middle childhood, with a 4- to 6-fold increase in the odds for anxiety disorders in VLBW children $(16,46)$. Using a DSM-based questionnaire, Hack et al. (43) recently reported prevalence estimates for anxiety disorders and depression that were two to three times higher for ELBW children than controls but these differences were not significant, only the risk for specific phobias was significantly increased. Most recently, in the UK EPICure Study, we have reported a $9 \%$ prevalence of emotional disorders in EPT children compared with $2 \%$ in term controls (OR: 4.6; Fig. 1) (47). This excess risk was accounted for by anxiety disorders (OR: 3.5), commonly separation anxiety and generalized anxiety disorder. Although in the general population, emotional disorders are associated with female sex and poor physical health (44), this was not so among EPT children in this study (44). Rather, the association was with cognitive impairment (47) as has also been found in VLBW children (16). During adolescence, there is typically an increase in emotional disorders, particularly for females (86). The fact that there are already high levels of these disorders present in EPT/ELBW children at 8-11 $\mathrm{y}$ of age is a cause for concern and suggests that the RR of these disorders may increase with age. There is thus a pressing need for routine screening to facilitate early psychological referral for emotional problems in this population.

\section{Continuity to Adult Life}

The extent to which behavioral problems and psychiatric disorders identified among VPT/VLBW children persist into adulthood in preterm populations is, as yet, largely unclear. Cohorts of children born in the 1990s are only now reaching adulthood and thus existing reports are focused on those more mature children born in the presteroid/surfactant era. Given the link between perinatal adversity and schizophrenia (1), one might expect to find higher rates of psychotic disorders in preterm populations in adulthood. Thought and withdrawal problems identified early in life may be precursors of psychotic disorders and thus follow-up into adulthood is crucial (19).

In a recent population linkage study, Moster et al. (87) found that the risk of ASD in adulthood increased significantly with decreasing GA. Prevalence rates increased sharply with birth below $31 \mathrm{wk}$, with $0.4 \%$ prevalence at $28-30 \mathrm{wk}$ and $0.6 \%$ prevalence at $23-27 \mathrm{wk}$. These rates represented an RR of 7.3 and 9.7 , respectively, compared with term peers. In contrast, the association between schizophrenia and GA was of a similar order but not statistically significant. With a lifetime prevalence of $1.0-1.5 \%$, it may be difficult to show an excess of schizophrenia in prospective studies.

Using hospital diagnosis linkage, Lindström et al. (88) found an excess of psychiatric and addictive disorders in VPT adults with significantly lower prevalence in families with higher socioeconomic status. Although these rates were significantly elevated in VPT adults, $85 \%$ of the population attributable risk was due to disorders in moderate-late preterm and early term-born individuals. In contrast, in the Helsinki VLBW Adult Study, executive dysfunction and emotional instability were no more common in VLBW adults who were of appropriate birthweight for gestation than controls, and these VLBW adults had lower 
scores on subscales assessing alcohol abuse and risk-taking behaviors. However, VLBW small-for-GA adults had higher scores compared with controls for executive dysfunction and emotional instability, particularly for depression (89).

In other prospective longitudinal studies, a similar pattern of behaviors to the childhood profile was found with more internalizing behaviors (OR: 2.2) (90) and an increased rate of prescriptions for depression among ELBW adults (91). Generally, among VLBW/ELBW populations, reports indicate less risk taking behaviors and alcohol abuse $(89,92)$ leading to the speculation that this is a reflection of poor socialization and internalizing symptoms among such individuals. However, no long-term outcomes in adult life after childhood diagnostic studies have been reported and continuity, although anticipated, is more inferred than demonstrated.

\section{Conclusions}

Despite elevated rates of psychiatric disorders in childhood among preterm children, it must be emphasized that most are found in association with other morbidities, particularly cognitive impairment. The most prevalent disorders are ADHD (inattentive subtype), anxiety, and ASD. These comprise a reasonably consistent preterm phenotype which is also manifest in high rates of subclinical symptomatology. Population level registries comprise few babies of extremely low GAs because survival has improved mainly in the past $20 \mathrm{y}$, but there does appear to be a GA gradient with a tendency in most studies to more frequent symptoms at lower gestations. Prospective longitudinal studies are relatively small and have low power to detect rare conditions. Although we have emphasized the relatively high rates of pathology among the most immature survivors, the population attributable risk of psychiatric disorders is low in comparison to children born as late preterm and early term births. Nonetheless, the high rates of psychopathology observed suggest that mental health surveillance for these vulnerable individuals would be beneficial.

\section{REFERENCES}

1. Dalman C, Allebeck P, Cullberg J, Grunewald C, Koster M 1999 Obstetric complications and the risk of schizophrenia: a longitudinal study of a national birth cohort. Arch Gen Psychiatry 56:234-240

2. Abel KM, Wicks S, Susser ES, Dalman C, Pedersen MG, Mortensen PB, Webb RT 2010 Birth weight, schizophrenia, and adult mental disorder: is risk confined to the smallest babies? Arch Gen Psychiatry 67:923-930

3. Gale CR, Martyn CN 2004 Birth weight and later risk of depression in a national birth cohort. Br J Psychiatry 184:28-33

4. Nomura Y, Brooks-Gunn J, Davey C, Ham J, Fifer WP 2007 The role of perinatal problems in risk of co-morbid psychiatric and medical disorders in adulthood. Psychol Med 37:1323-1334

5. Patton GC, Coffey C, Carlin JB, Olsson CA, Morley R 2004 Prematurity at birth and adolescent depressive disorder. Br J Psychiatry 184:446-447

6. Linnet KM, Wisborg K, Agerbo E, Secher NJ, Thomsen PH, Henriksen TB 2006 Gestational age, birth weight, and the risk of hyperkinetic disorder. Arch Dis Child 91:655-660

7. Schendel D, Bhasin TK 2008 Birth weight and gestational age characteristics of children with autism, including a comparison with other developmental disabilities. Pediatrics 121:1155-1164

8. Larsson HJ, Eaton WW, Madsen KM, Vestergaard M, Oleson AV, Agerbo E, Schendel D, Thorsen P, Mortensen PB 2005 Risk factors for autism: perinatal factors, parental psychiatric history, and socioeconomic status. Am J Epidemiol $161: 916-925$

9. Williams K, Helmer M, Duncan GW, Peat JK, Mellis CM 2008 Perinatal and maternal risk factors for autism spectrum disorders in New South Wales, Australia. Child Care Health Dev 34:249-256

10. Burd L, Severud R, Kerbeshian J, Klug MG 1999 Prenatal and perinatal risk factors for autism. J Perinat Med 27:441-450
11. Kapellou O, Counsell SJ, Kennea N, Dyet L, Saeed N, Stark J, Maalouf E, Duggan P, Ajayi-Obe M, Hajnal J, Allsop JM, Boardman J, Rutherford MA, Cowan F, Edwards AD 2006 Abnormal cortical development after premature birth shown by altered allometric scaling of brain growth. PLoS Med 3:e265

12. Himmelmann K, Hagberg G, Beckung E, Hagberg B, Uvebrant P 2005 The changing panorama of cerebral palsy in Sweden. IX. Prevalence and origin in the birth-year period 1995-1998. Acta Paediatr 94:287-294

13. Marlow N 2005 Outcome following preterm birth. In: Rennie JM (ed) Roberton's Textbook of Neonatology. Elsevier Limited, Philadelphia, PA, pp 63-82

14. Johnson S 2007 Cognitive and behavioural outcomes following very preterm birth. Semin Fetal Neonatal Med 12:363-373

15. MacKay DF, Smith GC, Dobbie R, Pell JP 2010 Gestational age at delivery and special educational need: retrospective cohort study of 407, 503 school children. PLoS Med 7:e1000289

16. Indredavik MS, Vik T, Heyerdahl S, Kulseng S, Fayers P, Brubakk AM 2004 Psychiatric symptoms and disorders in adolescents with low birth weight. Arch Dis Child Fetal Neonatal Ed 89:F445-F450

17. Achenbach TM 1991 Manual for the Child Behavior Checklist/4-18 and 1991 Profile. University of Vermont, Burlington, VT

18. Bhutta AT, Cleves MA, Casey PH, Cradock MM, Anand KK 2002 Cognitive and behavioral outcomes of school-aged children who were born preterm. a metaanalysis. JAMA 288:728-737

19. Elgen I, Sommerfelt K, Markestad T 2002 Population based, controlled study of behavioural problems and psychiatric disorders in low birthweight children at 11 years of age. Arch Dis Child Fetal Neonatal Ed 87:F128-F132

20. Sommerfelt K, Troland K, Ellertsen B, Markestad T 1996 Behavioral problems in low-birthweight preschoolers. Dev Med Child Neurol 38:927-940

21. Stevenson CJ, Blackburn P, Pharoah PO 1999 Longitudinal study of behaviour disorders in low birthweight infants. Arch Dis Child Fetal Neonatal Ed 81:F5-F9

22. Pharoah PO, Stevenson CJ, Cooke RW, Stevenson RC 1994 Prevalence of behaviour disorders in low birthweight infants. Arch Dis Child 70:271-274

23. Reijneveld SA, de Kleine MJ, van Baar AL, Kollée LA, Verhaak CM, Verhulst FC, Verloove-Vanhorick SP 2006 Behavioural and emotional problems in very preterm and very low birthweight infants at age 5 years. Arch Dis Child Fetal Neonatal Ed 91:F423-F428

24. Delobel-Ayoub M, Arnaud C, White-Koning M, Casper C, Pierrat V, Garel M, Burguet A, Roze J, Matis J, Picaud J, Kaminski M, Larroque B 2009 Behavioral problems and cognitive performance at 5 years of age after very preterm birth: The EPIPAGE Study. Pediatrics 123:1485-1492

25. Dahl LB, Kaaresen PI, Tunby J, Handegård BH, Kvernmo S, Rønning JA 2006 Emotional, behavioral, social, and academic outcomes in adolescents born with very low birth weight. Pediatrics 118:e449-e459

26. Taylor HG, Klein N, Minich N, Hack M 2000 Middle school-age outcomes in children with very low birth-weight. Child Dev 71:1495-1511

27. Stjernqvist K, Svenningsen NW 1999 Ten-year follow-up of children born before 29 gestational weeks: health, cognitive development, behaviour and school achievement. Acta Paediatr 88:557-562

28. Farooqi A, Hagglof B, Sedin G, Gothefors L, Serenius F 2007 Mental health and social competencies of 10- to 12-year-old children born at 23 to 25 weeks of gestation in the: a Swedish national prospective follow-up study. Pediatrics 120:118-133

29. Samara M, Marlow N, Wolke D 2008 Pervasive behavior problems at 6 years of age in a total-population sample of children born at $<25$ weeks of gestation. Pediatrics 122:562-573

30. Grunau RE, Whitfield MF, Fay TB 2004 Psychosocial and academic characteristics of extremely low birth weight $(\leq 800 \mathrm{~g})$ adolescents who are free of major impairment compared with term-born control subjects. Pediatrics 114:e725-e732

31. van Baar AL, Vermaas J, Knots E, de Kleine MJ, Soons P 2009 Functioning at school age of moderately preterm children born at 32 to 36 weeks' gestational age. Pediatrics 124:251-257

32. Huddy CL, Johnson A, Hope PL 2001 Educational and behavioural problems in babies of 32-35 weeks gestation. Arch Dis Child Fetal Neonatal Ed 85:F23-F28

33. Gurka MJ, LoCasale-Crouch J, Blackman JA 2010 Long-term cognition, achievement, socioemotional, and behavioral development of healthy late-preterm infants. Arch Pediatr Adolesc Med 164:525-532

34. Anderson P, Doyle LW 2003 Neurobehavioral outcomes of school-age children born extremely low birth weight or very preterm in the 1990s. JAMA 289:3264-3272

35. Aarnoudse-Moens CS, Weisglas-Kuperus N, van Goudoever JB, Oosterlan J 2009 Meta-analysis of neurobehavioural outcomes in very preterm and/or very low birth weight children. Pediatrics 124:717-728

36. Hille ET, den Ouden AL, Saigal S, Wolke D, Lambert M, Whitaker A, Pinto-Martin JA, Hoult L, Meyer R, Feldman JF, Verloove-Vanhorick SP, Paneth N 2001 Behavioural problems in children who weigh $1000 \mathrm{~g}$ or less at birth in four countries. Lancet 357:1641-1643

37. Goodman R 1997 The Strengths and Difficulties Questionnaire: a research note. J Child Psychol Psychiatry 38:581-586

38. Gardner F, Johnson A, Yudkin P, Bowler U, Hockley C, Mutch L, Wariyar U 2004 Behavioral and emotional adjustment of teenagers in mainstream school who were born before 29 weeks' gestation. Pediatrics 114:676-682

39. Indredavik MS, Vik T, Heyerdahl S, Kulseng S, Brubakk AM 2005 Psychiatric symptoms in low birth weight adolescents, assessed by screening questionnaires. Eur Child Adolesc Psychiatry 14:226-236

40. American Psychiatric Association 2000 Diagnostic and Statistical Manual of Mental Disorders. 4th ed. Text Revision. American Psychiatric Association, Washington DC 
41. Szatmari P, Saigal S, Rosembaum P, Campbell D, King S 1990 Psychiatric disorder at five years among children with birthweights $<1000 \mathrm{~g}$ : a regional perspective. Dev Med Child Neurol 32:954-962

42. Szatmari P, Saigal S, Rosenbaum P, Campbell D 1993 Psychopathology an adaptive functioning among extremely low birthweight children at eight years of age. Dev Psychopathol 5:345-357

43. Hack M, Taylor HG, Schlichter M, Andreias L, Drotar D, Klein N 2009 Behavioral outcomes of extremely low birth weight children at age 8 years. J Dev Behav Pediatr 30:122-130

44. Green H, McGinnity A, Meltzer H, Ford T, Goodman R 2005 Mental Health of Children and Young People in Great Britain, 2004. Available at: www.statistics. gov.uk/downloads/theme_health/GB2004.pdf. Accessed January 28, 2011

45. Whitaker AH, Van Rossem R, Feldman JF, Schonfeld IS, Pinto-Martin JA, Tore C, Shaffer D, Paneth N 1997 Psychiatric outcomes in low-birth-weight children at age 6 years: relation to neonatal cranial ultrasound abnormalities. Arch Gen Psychiatry 54:847-856

46. Botting N, Powls A, Cooke R, Marlow N 1997 Attention deficit hyperactivity disorder and other psychiatric outcomes in very low birthweight children at 12 years. J Child Psychol Psychiatry 38:931-941

47. Johnson S, Hollis C, Hennessy E, Kochhar P, Wolke D, Marlow N 2010 Psychiatric disorders in extremely preterm children. J Am Acad Child Adolesc Psychiatry 49:453-463

48. Hintz SR, Kendrick DE, Vohr BR, Poole WK, Higgins RD 2006 Gender differences in neurodevelopmental outcomes among extremely preterm, extremely-lowbirthweight infants. Acta Paediatr 95:1239-1248

49. Brothwood M, Wolke D, Gamsu H, Benson J, Cooper D 1986 Prognosis of the very low birthweight baby in relation to gender. Arch Dis Child 61:559-564

50. Indredavik MS, Vik T, Evensen AI, Skranes J, Taraldsen G, Brubakk A 2010 Perinatal risk and psychiatric outcome in adolescents born preterm with very low birth weight or term small for gestational age. J Dev Behav Pediatr 31:286-294

51. O'Callaghan MJ, Burns YR, Gray PH, Harvey JM, Mohay H, Rogers YM, Tudehope DI 1996 School performance of ELBW children: a controlled study. Dev Med Child Neurol 38:917-926

52. Ross G, Lipper EG, Auld PA 1991 Educational status and school-related abilities of very low birth weight premature children. Pediatrics 88:1125-1134

53. Foulder-Hughes LA, Cooke RW 2003 Motor, cognitive, and behavioural disorders in children born very preterm. Dev Med Child Neurol 45:97-103

54. Mick E, Biederman J, Prince J, Fischer MJ, Faraone SV 2002 Impact of low birth weight on attention-deficit hyperactivity disorder. J Dev Behav Pediatr 23:16-22

55. Shum D, Neulinger K, O'Callaghan M, Mohay H 2008 Attentional problems in children born with very preterm of with extremely low birth weight at 7-9 years. Arch Clin Neuropsychol 23:103-112

56. World Health Organization 1992 The ICD-10 Classification of Mental and Behavioural Disorders: Clinical Descriptions and Diagnostic Guidelines. Available at: http://www.who.int/classifications/icd/en/bluebook.pdf. Accessed January 28, 2011

57. Peterson BS, Vohr B, Staib LH, Cannistraci CJ, Dolberg A, Schneider KC, Katz KH, Westerveld M, Sparrow S, Anderson AW, Duncan CC, Makuch RW, Gore JC, Ment LR 2000 Regional brain volume abnormalities and long-term cognitive outcome in preterm infants. JAMA 284:1939-1947

58. Rushe TM, Rifkin L, Stewart AL, Townsend JP, Roth SC, Wyatt JS, Murray RM 2001 Neuropsychological outcome at adolescence of very preterm birth and its relation to brain structure. Dev Med Child Neurol 43:226-233

59. Peterson J, Taylor HG, Minich N, Klein N, Hack M 2006 Subnormal hea circumference in very low birth weight children: neonatal correlates and school-age consequences. Early Hum Dev 82:325-334

60. Stewart AL, Rifkin L, Amess PN, Kirkbride V, Townsend JP, Miller DH, Lewis SW, Kingsley DP, Moseley IF, Foster O, Murray RM 1999 Brain structure and neurocognitive and behavioural function in adolescents who were born very preterm. Lancet 353:1653-1657

61. O'Callaghan MJ, Harvey JM 1997 Biological predictors and co-morbidity of attention deficit and hyperactivity disorder in extremely low birthweight infants at school. J Paediatr Child Health 33:491-496

62. Indredavik MS, Skranes JS, Vok T, Heyerdahl S, Romundstad P, Myhr GE, Brubakk AM 2005 Low-birth-weight adolescents: psychiatric symptoms and cerebral MRI abnormalities. Pediatr Neurol 33:259-266

63. Skranes J, Vangberg TR, Kulseng S, Indredavik MS, Evensen KA, Martinussen M, Dale AM, Haraldseth O, Brubakk A-M 2007 Clinical findings and white matter abnormalities seen on diffusion tensor imaging in adolescents with very low birth weight. Brain 130:654-666

64. Martel MM, von Eye A, Nigg JT 2010 Revisiting the latent structure of ADHD: is there a 'g' factor? J Child Psychol Psychiatry 51:905-914

65. Grizenko N, Paci M, Joober R 2010 Is the inattentive subtype of ADHD different from the combined/hyperactive subtype? J Atten Disord 13:649-657

66. Faraone SV, Biederman J, Weber W, Russell RL 1998 Psychiatric, neuropsychological, and psychosocial features of DSM subtypes of attention-deficit/hyperactivit disorder: results from a clinically referred sample. J Am Acad Child Adolesc Psychiatry 37:185-193

67. Diamond A 2005 Attention-deficit disorder (attention-deficit/hyperactivity disorder without hyperactivity): a neurobiologially and behaviorally distinct disorder from attention-deficit/hyperactivity disorder (with hyperactivity). Dev Psychopathol 17:807-825

68. Mulder H, Pitchford NJ, Marlow N 2010 Processing speed and working memory underlie academic attainment in very preterm children. Arch Dis Child Fetal Neonatal Ed 95:F267-F272

69. Wolke D 1998 Psychological development of prematurely born children. Arch Dis Child 78:567-570

70. Johnson S, Hennessy E, Smith R, Trikic R, Wolke D, Marlow N 2009 Academic attainment and special educational needs in extremely preterm children at 11 years. The EPICure Study. Arch Dis Child Fetal Neonatal Ed 94:F283-F289

71. Nadeau L, Boivin M, Tessier R, Lefebvre F, Robaey P 2001 Mediators of behavioral problems in 7-year-old children born after 24 to 28 weeks of gestation. J Dev Behav Pediatr 22:1-10

72. Fombonne E 2009 Epidemiology of pervasive developmental disorders. Pediatr Res 65:591-598

73. Kolevzon A, Gross R, Reichenberg A 2007 Prenatal and perinatal risk factors for autism. Arch Pediatr Adolesc Med 161:326-333

74. Johnson S, Hollis C, Kochhar P, Hennessy E, Wolke D, Marlow N 2010 Autism spectrum disorders in extremely preterm children. J Pediatr 156:525-531

75. Williams JG, Brayne CE, Higgins JP 2006 Systematic review of prevalence studies of autism spectrum disorders. Arch Dis Child 91:8-15

76. Robins DL, Fein D, Barton ML, Green JA 2001 The Modified Checklist for Autism in Toddlers: an initial study investigating the early detection of autism and pervasive developmental disorders. J Autism Dev Disord 31:131-144

77. Limperopoulos C, Bassan H, Sullivan NR, Soul JS, Robertson RL, Moore M, Ringer SA, Volpe J, du Plessis AJ 2008 Positive screening for autism in ex-preterm infants: prevalence and risk factors. Pediatrics 121:758-765

78. Kuban KC, O'Shea TM, Allred EN, Tager-Flusberg H, Goldstein DJ, Leviton A 2009 Positive screening on the Modified Checklist for Autism in Toddlers (MCHAT) in extremely low gestational age newborns. J Pediatr 154:535-540.e1

79. Johnson S, Marlow N 2009 Positive screening results on the modified checklist for autism in toddlers: implications for very preterm populations J Pediatr 154:478-480

80. Rutter M, Bailey A, Bolton P, LeCouter A 1994 Autism and known medical conditions: myth and substance. J Child Psychol Psychiatry 35:311-322

81. Rutter M, Andersen-Wood L, Beckett C, Bredenkamp D, Castle J, Groothues C, Kreppner J, Keaveney L, Lord C, O'Connor TG 1999 Quasi-autistic patterns following severe early global privation. English and Romanian Adoptees (ERA) Study Team. J Child Psychol Psychiatry 40:537-549

82. Kreppner JM, Rutter M, Beckett C, Castle J, Colvert E, Groothues C, Hawkins A O'Connor TG, Stevens S, Sonuga-Barke EJ 2007 Normality and impairment following profound early institutional deprivation: a longitudinal follow-up into early adolescence. Dev Psychol 43:931-946

83. Anand KJ, Scalzo FM 2000 Can adverse neonatal experiences alter brain development and subsequent behavior? Biol Neonate 77:69-82

84. Saigal S, Pinelli J, Hoult L, Kim MM, Boyle M 2003 Psychopathology and social competencies of adolescents who were extremely low birth weight. Pediatrics 111:969-975

85. Bayless SJ, Pit-ten Cate IM, Stevenson J 2008 Behaviour difficulties and cognitive function in children born very prematurely. Int J Behav Dev 32:199-206

86. Costello EJ, Pine DS, Hammen C, March JS, Plotsky PM, Weissman MM, Biederman J, Goldsmith HH, Kaufman J, Lewinsohn PM, Hellander M, Hoagwood K Koretz DS, Nelson CA, Leckman JF 2002 Development and natural history of mood disorders. Biol Psychiatry 52:529-542

87. Moster D, Terje R, Markestad T 2008 Long-term medical and social consequences of preterm birth. N Engl J Med 359:262-273

88. Lindström K, Lindblad F, Hjern A 2009 Psychiatric morbidity in adolescents and young adults born preterm: a Swedish national cohort study. Pediatrics 123:e47-e53

89. Strang-Karlsson S, Räikkönen K, Pesonen AK, Kajantie E, Paavonen EJ, Lahti J, Hovi P, Heinonen K, Järvenpää AL, Eriksson JG, Andersson S 2008 Very low birth weight and behavioral symptoms of attention deficit hyperactivity disorder in young adulthood: the Helsinki study of very-low-birth-weight adults. Am J Psychiatry 165:1345-1353

90. Hack M, Youngstrom EA, Cartar L, Schluchter M, Taylor HG, Flannery D, Klein N, Borawski E 2004 Behavioral outcomes and evidence of psychopathology among very low birth weight infants at age 20 years. Pediatrics 114:932-940

91. Saigal S, Stoskopf B, Streiner DL, Boyle M, Pinelli J, Paneth N, Goddeeris J 2006 Transition of extremely low-birth weight infants from adolescence to young adulthood. Comparison with normal birth-weight controls. JAMA 295:667-675

92. Hack M, Flannery D, Schluchter M, Cartar L, Borawski E, Klein N 2002 Outcomes in young adulthood for very-low-birth-weight infants. N Engl J Med 346:149-157 